\title{
Association of Glucose Fluctuations with Sarcopenia in Older Adults with Type 2 Diabetes Mellitus
}

\author{
Noriko Ogama $1,2,3$, Takashi Sakurai ${ }^{1,4, *}$, Shuji Kawashima ${ }^{2,5}$, Takahisa Tanikawa ${ }^{5,6}$, \\ Haruhiko Tokuda 5,6,7, Shosuke Satake ${ }^{2}$, Hisayuki Miura ${ }^{8}$, Atsuya Shimizu ${ }^{9}$, \\ Manabu Kokubo ${ }^{9}$, Shumpei Niida ${ }^{7}$, Kenji Toba ${ }^{1}$, Hiroyuki Umegaki ${ }^{3}$ and \\ Masafumi Kuzuya ${ }^{3,10}$ \\ 1 Center for Comprehensive Care and Research on Memory Disorders, National Center for Geriatrics and \\ Gerontology, Obu 474-8511, Japan; n-ogama@ncgg.go.jp (N.O.); toba@ncgg.go.jp (K.T.) \\ 2 Department of Geriatric Medicine, National Center for Geriatrics and Gerontology, Obu 474-8511, Japan; \\ kawashu@ncgg.go.jp (S.K.); satakes@ncgg.go.jp (S.S.) \\ 3 Department of Community Healthcare and Geriatrics, Nagoya University Graduate School of Medicine, \\ Nagoya 466-8550, Japan; umegaki@med.nagoya-u.ac.jp (H.U.); kuzuya@med.nagoya-u.ac.jp (M.K.) \\ 4 Department of Cognition and Behavior Science, Nagoya University Graduate School of Medicine, \\ Nagoya 466-8550, Japan \\ 5 Department of Endocrinology and Metabolism, National Center for Geriatrics and Gerontology, \\ Obu 474-8511, Japan; hoisan@ncgg.go.jp (T.T.); tokuda@ncgg.go.jp (H.T.) \\ 6 Department of Clinical Laboratory, National Center for Geriatrics and Gerontology, Obu 474-8511, Japan \\ 7 Medical Genome Center, National Center for Geriatrics and Gerontology, Obu 474-8511, Japan; \\ sniida@ncgg.go.jp \\ 8 Department of Home Care Coordinators, National Center for Geriatrics and Gerontology, Obu 474-8511, \\ Japan; hmiura@ncgg.go.jp \\ 9 Department of Cardiology, National Center for Geriatrics and Gerontology, Obu 474-8511, Japan; \\ ashimizu@ncgg.go.jp (A.S.); mkokubo@ncgg.go.jp (M.K.) \\ 10 Institutes of Innovation for Future Society, Nagoya University, Nagoya 464-8601, Japan \\ * Correspondence: tsakurai@ncgg.go.jp; Tel.: +81-562-46-2311
}

Received: 31 January 2019; Accepted: 28 February 2019; Published: 6 March 2019

\begin{abstract}
Type 2 diabetes mellitus accelerates loss of muscle mass and strength. Patients with Alzheimer's disease (AD) also show these conditions, even in the early stages of AD. The mechanism linking glucose management with these muscle changes has not been elucidated but has implications for clarifying these associations and developing preventive strategies to maintain functional capacity. This study included 69 type 2 diabetes patients with a diagnosis of cognitive impairment $(n=32)$ and patients with normal cognition $(n=37)$. We investigated the prevalence of sarcopenia in diabetes patients with and without cognitive impairment and examined the association of glucose alterations with sarcopenia. Daily glucose levels were evaluated using self-monitoring of blood glucose, and we focused on the effects of glucose fluctuations, postprandial hyperglycemia, and the frequency of hypoglycemia on sarcopenia. Diabetes patients with cognitive impairment displayed a high prevalence of sarcopenia, and glucose fluctuations were independently associated with sarcopenia, even after adjusting for glycated hemoglobin $\mathrm{A} 1 \mathrm{c}(\mathrm{HbA} 1 \mathrm{c})$ levels and associated factors. In particular, glucose fluctuations were significantly associated with a low muscle mass, low grip strength, and slow walking speed. Our observation suggests the importance of glucose management by considering glucose fluctuations to prevent the development of disability.
\end{abstract}

Keywords: Alzheimer's disease; type 2 diabetes mellitus; glucose fluctuations; sarcopenia 


\section{Introduction}

The definition and diagnosis of sarcopenia were updated by the European Working Group on Sarcopenia in Older People [1]. The revised consensus focuses on the importance of promoting early detection and treatment of sarcopenia [1]. Because sarcopenia predicts adverse outcomes such as chronic disease progression, mortality, and functional disability [2], developing strategies to prevent sarcopenia in older adults is necessary.

Older adults with type 2 diabetes have a higher prevalence of sarcopenia than non-diabetic individuals [3,4]. Some studies have reported that increased glycated hemoglobin A1c (HbA1c) levels are associated with impaired muscle quality, muscle strength and physical performance [5-7]. However, $\mathrm{HbA} 1 \mathrm{c}$ levels do not adequately reflect the mean glucose concentration and are not associated with hypoglycemic risk in diabetes patients [8,9]. Severe hypoglycemic events lead to deterioration in general health, resulting in an increased risk of mobility disabilities [10]. Therefore, continuous assessments of daily glucose excursions are needed to determine the association of glucose management with sarcopenia.

Muscle changes and physical dysfunctions are observed in the early stages of Alzheimer's disease (AD) [11,12]. Lean mass is reduced in early AD and is associated with brain atrophy [11]. Furthermore, the nutritional status is correlated with regional cerebral glucose metabolism in prodromal AD, and the prevalence of sarcopenia increases with the degree of cognitive decline [13,14]. These studies suggest that AD-related degenerative pathologies have a negative impact on muscle structure and physical function. Additionally, AD patients with diabetes have a variety of difficulties in glucose management and therefore might have a higher prevalence of sarcopenia than diabetes patients without AD. However, to date, the prevalence of sarcopenia in diabetes patients with and without cognitive impairment remains unclear. Furthermore, the association of glucose management with sarcopenia in these patients is also unknown.

The aims of this study were as follows: (1) to clarify the prevalence of sarcopenia in older type 2 diabetes patients with cognitive impairment or normal cognition, and (2) to clarify the association of glucose management with sarcopenia in these patients. We hypothesized that diabetes patients with cognitive impairment would display a high prevalence of sarcopenia and that abnormal glucose profiles would be associated with muscle changes and physical dysfunction.

\section{Methods}

\subsection{Participants}

The study was conducted in accordance with the Declaration of Helsinki, and the protocol was approved by the Ethics Committee of the National Center for Geriatrics and Gerontology (NCGG) (approval no. 682). All participants provided written informed consent before participating in the study. We included 69 outpatients (cognitive impairment: $n=32$; normal cognition: $n=37$ ) who visited the NCGG hospital from 2014 to 2016. The presence of cognitive impairment was defined as probable or possible $\mathrm{AD}$ and amnestic mild cognitive impairment (aMCI) according to the criteria of the National Institute on Aging-Alzheimer's Association workgroups and the definition provided by Petersen et al. $[15,16]$. Persons with NC attended NCGG hospital for suspected memory impairment but were assessed as having normal cognition. Patients meeting all the following criteria were included in this study: (1) outpatients with type 2 diabetes treated with antidiabetic agents; (2) aged 65 years or older; (3) living in their houses; (4) with families or caregivers who support self-monitoring of blood glucose (SMBG); and (5) a Mini-Mental State Examination (MMSE) score $\geq 10$ for cognitive impairment. The exclusion criteria were as follows: (1) severe hearing loss and visual impairment; (2) severe health conditions, such as cardiac failure, renal disorder or liver dysfunction; and (3) neurological disorders other than AD or aMCI. 


\subsection{Assessment of Clinical Parameters and Comorbidities Associated with Diabetes}

Clinical data and blood samples were distributed from the Biobank, which collects and stores biological material and associated clinical data for biomedical research. Data on the diagnosis, antidiabetic medication use, and polypharmacy (defined as taking five or more types of oral medicine) [17] were obtained from clinical charts. Global cognitive function was assessed by the MMSE [18]. Diabetes-associated complications were evaluated for the coexistence of neuropathy, retinopathy and nephropathy [19]. Diabetic neuropathy was defined as either the loss of Achilles tendon reflex or the presence of neuropathic symptoms. Diabetic retinopathy was fundoscopically assessed through dilated pupils by experienced ophthalmologists. Diabetic nephropathy was defined as an albumin-to-creatinine ratio $>300 \mu \mathrm{g} / \mathrm{mg}$ or a urinary protein concentration $>0.5 \mathrm{mg} / \mathrm{dL}$. We obtained information on the following biochemical parameters: $\mathrm{HbA} 1 \mathrm{c}$, triglyceride, total cholesterol, high-density lipoprotein cholesterol, low-density lipoprotein cholesterol, estimated glomerular filtration rate, serum albumin, and urinary albumin. HbA1c levels were expressed in the National Glycohemoglobin Standardization Program units.

\subsection{Measurement of Daily Glucose Levels}

Daily glucose levels were recorded by SMBG (MS-FR201B; Terumo Corp., Tokyo, Japan) and were measured at five time points per day $(05: 00 \mathrm{~h}$, before breakfast, $2 \mathrm{~h}$ after breakfast, before lunch, and before dinner) on eight separate days during a two-month period. Glucose levels usually nadir early in the morning and before each meal, and postprandial glucose levels usually peak at $2 \mathrm{~h}$ after breakfast [20]. Therefore, we evaluated the glucose levels at these time points. When diabetic patients with cognitive impairment used SMBG, their families helped with the measurement. Hypoglycemia was defined as a glucose level $\leq 70 \mathrm{mg} / \mathrm{dL}$ [21], and the presence or absence of hypoglycemic symptoms was recorded at every SMBG measurement point. Glucose fluctuations were determined based on the diurnal range from minimum glucose levels to maximum glucose levels.

\subsection{Evaluation of Sarcopenia}

Sarcopenia was defined as low muscle mass plus low muscle strength and/or low physical performance according to the Asian Working Group for Sarcopenia (AWGS) [22]. Low muscle mass was defined as a calf circumference $<31 \mathrm{~cm}$ [23], which was measured with the patient in the supine position with the left knee raised at a right angle from the thigh. Calf circumference was correlated with appendicular skeletal muscle mass measured by dual-energy X-ray absorptiometry and has been proposed as a surrogate marker of muscle mass for diagnosing sarcopenia [24]. Low muscle strength was determined by low hand grip strength ( $<26 \mathrm{~kg}$ in men and $<18 \mathrm{~kg}$ in women). Hand grip strength was measured with a Smedley dynamometer (Matsumiya Medical Instruments, Tokyo, Japan). Low physical performance was assessed by slow walking speed. The presence of slow walking speed was defined as individuals who answered "No" to the following question: "Can you cross the road within the green signal interval?" [25].

\subsection{Statistical Analysis}

All analyses were performed using SPSS for Windows version 22.0 (IBM Corp., Armonk, NY, USA). The distributions of data were assessed for normality using the Shapiro-Wilk test. Differences in demographics between diabetic patients with cognitive impairment and patients with normal cognition were examined by unpaired $t$-tests (for parametric variables) or the Mann-Whitney $\mathrm{U}$ test (for non-parametric variables). Categorical variables were analyzed by the chi-squared test or Fisher's exact test. Differences in glucose levels with and without sarcopenia were analyzed using unpaired $t$-tests or the Mann-Whitney $\mathrm{U}$ test. To identify the factors associated with sarcopenia, we performed logistic regression analysis. First, we conducted stepwise analysis to select the most influential glucose index for sarcopenia. Next, we conducted logistic regression with forward variable 
selection to construct a model based on the variables associated with sarcopenia, defined as those with $p<0.05$, adjusted for factors related to the development of sarcopenia (i.e., age, HbA1c level and the presence of diabetic neuropathy) [4,5,7]. In this analysis, we calculated the adjusted odds ratio (OR) and 95\% confidence interval (CI) for factors associated with sarcopenia. The dependent variable was sarcopenia, and the independent variable was the glucose index, which was selected as the most influential variable associated with sarcopenia in a first regression analysis. Statistical significance was set at $p<0.05$.

\section{Results}

\subsection{Clinical Characteristics of the Study Participants}

The demographics of the participants are shown in Table 1. No differences in age, sex, body mass index, diabetic comorbidities or medication use were found between the diabetic patients with cognitive impairment and the normal cognition group. The cognitive impairment group had a lower MMSE score than the normal cognition group. Serum triglyceride levels were higher and albumin concentrations were lower in the cognitive impairment group, but the other metabolic markers did not differ between the groups. Regarding the average glucose levels during the 2 months of study, the glucose level before lunch was high in the cognitive impairment group. The prevalence of sarcopenia, represented by a low muscle mass, low grip strength and slow walking speed, was higher in the cognitive impairment group than that in the normal cognition group.

Table 1. Clinical characteristics of the study participants.

\begin{tabular}{|c|c|c|c|c|c|c|c|}
\hline & \multicolumn{2}{|c|}{ Total $(n=69)$} & \multicolumn{2}{|c|}{$\begin{array}{c}\text { Cognitive Impairment } \\
(n=32)\end{array}$} & \multicolumn{2}{|c|}{ Normal Cognition $(n=37)$} & \multirow{2}{*}{$p$-Value $^{\dagger}$} \\
\hline & $\begin{array}{c}\text { Mean (SD) or } \\
n(\%)\end{array}$ & Min-Max & $\begin{array}{c}\text { Mean (SD) or } \\
n(\%)\end{array}$ & Min-Max & $\begin{array}{c}\text { Mean (SD) or } \\
n(\%)\end{array}$ & Min-Max & \\
\hline Age, years & $75.0(5.3)$ & $65-87$ & $76.0(5.8)$ & $65-87$ & $74.2(4.7)$ & $65-83$ & 0.146 \\
\hline Male, $n(\%)$ & $36(52.2)$ & & $15(46.9)$ & & $21(56.8)$ & & 0.413 \\
\hline Body mass index, $\mathrm{kg} / \mathrm{m}^{2}$ & $23.8(2.7)$ & $17.8-31.0$ & $23.6(2.6)$ & $17.8-29.4$ & $24.0(2.7)$ & $19.9-31.0$ & 0.597 \\
\hline Mini-Mental State Examination & $24.4(5.0)$ & $13-30$ & $21.0(5.2)$ & $13-29$ & $27.4(2.0)$ & $22-30$ & $<0.001$ \\
\hline \multicolumn{8}{|l|}{ Diabetes and comorbidities } \\
\hline Duration of diabetes, years & $15.3(10.8)$ & $2-48$ & $15.3(10.6)$ & $2-40$ & $15.4(11.0)$ & $2-48$ & 0.899 \\
\hline Diabetic neuropathy, $n(\%)$ & $45(65.2)$ & & $22(68.8)$ & & $23(62.2)$ & & 0.567 \\
\hline Diabetic retinopathy, $n(\%)$ & $16(23.2)$ & & $5(15.6)$ & & $11(29.7)$ & & 0.166 \\
\hline Diabetic nephropathy, $n(\%)$ & $21(30.4)$ & & $12(37.5)$ & & $9(24.3)$ & & 0.236 \\
\hline Coronary artery disease, $n(\%)$ & $15(21.7)$ & & $6(18.8)$ & & $9(24.3)$ & & 0.576 \\
\hline Hypertension, $n(\%)$ & $53(76.8)$ & & $24(75.0)$ & & $29(78.4)$ & & 0.740 \\
\hline \multicolumn{8}{|c|}{ Medications and antidiabetic agents, $n(\%)$} \\
\hline Polypharmacy & $56(81.2)$ & & $29(90.6)$ & & $27(73.0)$ & & 0.061 \\
\hline Biguanide & $20(29.0)$ & & $10(31.3)$ & & $10(27.0)$ & & 0.700 \\
\hline Thiazolidine & $8(11.6)$ & & $6(18.8)$ & & $2(5.4)$ & & 0.132 \\
\hline DPP4 inhibitor & $49(71.0)$ & & $23(71.9)$ & & $26(70.3)$ & & 0.884 \\
\hline Sulfonylurea & $40(58.0)$ & & $19(59.4)$ & & $21(56.8)$ & & 0.826 \\
\hline Insulin secretion promoter & $2(2.9)$ & & $2(6.3)$ & & $0(0.0)$ & & 0.211 \\
\hline$\alpha$-Glucosidase inhibitor & $16(23.2)$ & & $7(21.9)$ & & $9(24.3)$ & & 0.810 \\
\hline Insulin & $13(18.8)$ & & $7(21.9)$ & & $6(16.2)$ & & 0.549 \\
\hline GLP-1 receptor agonists & $2(2.9)$ & & $1(3.1)$ & & $1(2.7)$ & & 1.000 \\
\hline \multicolumn{8}{|l|}{ Biochemical parameters } \\
\hline $\mathrm{HbA} 1 \mathrm{c}, \%$ & $7.1(0.6)$ & $6.2-9.3$ & $7.3(0.7)$ & $6.2-9.3$ & $7.0(0.5)$ & $6.3-8.6$ & 0.107 \\
\hline Triglyceride, mg/dL & $139.8(69.4)$ & $44-330$ & $165.5(72.1)$ & $65-330$ & $117.6(57.2)$ & $44-279$ & 0.004 \\
\hline Total cholesterol, mg/dL & $190.3(41.1)$ & $108-316$ & $192.0(41.1)$ & $108-316$ & $188.9(41.6)$ & $137-309$ & 0.524 \\
\hline HDL cholesterol, mg/dL & $53.6(13.7)$ & $27-92$ & $50.8(13.6)$ & $27-83$ & $56.0(13.5)$ & $37-92$ & 0.112 \\
\hline LDL cholesterol, mg/dL & $109.2(36.0)$ & $46-238$ & $109.5(37.2)$ & $46-211$ & $108.9(35.4)$ & $67-238$ & 0.928 \\
\hline $\mathrm{eGFR}, \mathrm{mL} / \mathrm{min} / 1.73 \mathrm{~m}^{2}$ & $63.7(17.6)$ & $28.3-115.9$ & $64.8(16.9)$ & $28.3-110.3$ & $62.7(18.3)$ & $30.6-115.9$ & 0.621 \\
\hline Albumin, g/dL & $4.3(0.4)$ & $3.5-5.2$ & $4.2(0.3)$ & $3.5-5.2$ & $4.4(0.3)$ & $3.8-5.2$ & 0.014 \\
\hline $\mathrm{UACR}, \mathrm{mg} / \mathrm{gCr}$ & $156.7(339.4)$ & $1.5-1808.3$ & $167.1(349.2)$ & $1.5-1705.4$ & $147.8(335.3)$ & $2.7-1808.3$ & 0.516 \\
\hline \multicolumn{8}{|l|}{ Daily blood glucose level } \\
\hline $05: 00 \mathrm{~h}, \mathrm{mg} / \mathrm{dL}$ & $116.6(22.2)$ & $57-254$ & $113.5(19.6)$ & $57-205$ & $119.4(24.2)$ & $58-254$ & 0.485 \\
\hline Before breakfast, mg/dL & $123.0(21.7)$ & $51-215$ & $119.5(20.4)$ & 63-201 & $126.0(22.6)$ & $51-215$ & 0.216 \\
\hline $2 \mathrm{~h}$ after breakfast, $\mathrm{mg} / \mathrm{dL}$ & $180.7(34.3)$ & $68-383$ & $184.7(38.8)$ & $68-349$ & $177.3(29.9)$ & $72-383$ & 0.880 \\
\hline Before lunch, $\mathrm{mg} / \mathrm{dL}$ & $126.7(33.6)$ & $43-313$ & $137.3(38.5)$ & $43-313$ & $117.6(25.9)$ & $45-243$ & 0.011 \\
\hline Before dinner, $\mathrm{mg} / \mathrm{dL}$ & $134.9(27.5)$ & $55-331$ & $139.2(33.0)$ & $60-331$ & $131.2(21.3)$ & $55-267$ & 0.339 \\
\hline Fluctuation, $\mathrm{mg} / \mathrm{dL}$ & $91.4(28.5)$ & 32-155 & $97.0(29.7)$ & $49-155$ & $86.5(26.8)$ & $32-137$ & 0.127 \\
\hline Frequency of hypoglycemia * & $0.71(1.3)$ & $0-7$ & $0.72(1.5)$ & $0-7$ & $0.70(1.2)$ & $0-4$ & 0.719 \\
\hline
\end{tabular}


Table 1. Cont.

\begin{tabular}{|c|c|c|c|c|c|c|c|}
\hline & \multicolumn{2}{|c|}{ Total $(n=69)$} & \multicolumn{2}{|c|}{$\begin{array}{l}\text { Cognitive Impairment } \\
\qquad(n=32)\end{array}$} & \multicolumn{2}{|c|}{ Normal Cognition $(n=37)$} & \multirow{2}{*}{$p$-Value ${ }^{\dagger}$} \\
\hline & $\begin{array}{c}\text { Mean (SD) or } \\
n(\%)\end{array}$ & Min-Max & $\begin{array}{c}\text { Mean (SD) or } \\
n(\%)\end{array}$ & Min-Max & $\begin{array}{c}\text { Mean (SD) or } \\
n(\%)\end{array}$ & Min-Max & \\
\hline \multicolumn{8}{|l|}{ Mobility function } \\
\hline Sarcopenia, $n(\%)$ & $8(11.6)$ & & $7(21.9)$ & & $1(2.7)$ & & 0.021 \\
\hline Low muscle mass, $n(\%)$ & $10(14.5)$ & & $9(28.1)$ & & $1(2.7)$ & & 0.004 \\
\hline Low grip strength, $n(\%)$ & $24(34.8)$ & & $17(53.1)$ & & $7(18.9)$ & & 0.003 \\
\hline Slow walking speed, $n(\%)$ & $4(5.8)$ & & $4(12.5)$ & & $0(0.0)$ & & 0.042 \\
\hline
\end{tabular}

Data are presented as the mean (standard deviation) or as numbers and percentages. ${ }^{*}$ Indicates the per-patient averages at the measuring points during the study period. ${ }^{\dagger}$ The quantitative variables age, body mass index, eGFR, daily blood glucose levels before breakfast and fluctuation were examined by unpaired $t$-tests, and other quantitative variables were analyzed by the Mann-Whitney $U$ test. The categorical variables thiazolidine, insulin secretion promoter, and GLP-1 receptor agonists were examined by Fisher's exact test, and other categorical variables were analyzed by the chi-squared test. Abbreviations: DPP4, dipeptidyl peptidase 4; eGFR, estimated glomerular filtration rate; GLP-1, glucagon-like peptide-1; HbA1c, glycated hemoglobin A1c; HDL cholesterol, high-density lipoprotein cholesterol; LDL cholesterol, low-density lipoprotein cholesterol; UACR, urine albumin-to-creatinine ratio.

\subsection{Differences in Glucose Profiles According to Sarcopenia}

First, we examined the differences in glucose profiles with and without sarcopenia in all subjects (Figure 1). Patients with sarcopenia displayed larger fluctuations in daily glucose levels compared to non-sarcopenia patients (117.3 mg/dL vs. $88.0 \mathrm{mg} / \mathrm{dL}, p=0.005)$. In addition, patients with sarcopenia showed high glucose levels $2 \mathrm{~h}$ after breakfast and before lunch $(209.5 \mathrm{mg} / \mathrm{dL}$ vs. $177.0 \mathrm{mg} / \mathrm{dL}$, $p=0.011$, and $152.2 \mathrm{mg} / \mathrm{dL}$ vs. $123.4 \mathrm{mg} / \mathrm{dL}, p=0.037$, respectively).

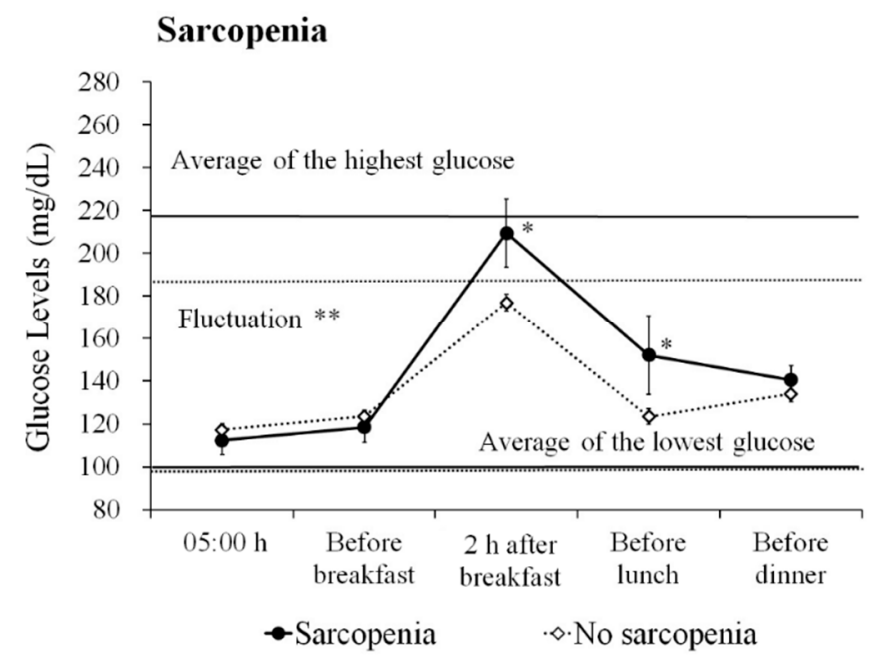

Figure 1. Daily glucose profiles based on sarcopenia. The figure shows the average \pm standard error (SE) glucose level based on sarcopenia in all participants. Average of the highest glucose level: the average of the maximum glucose level of the day during the measurement period. Average of the lowest glucose level: the average of the minimum glucose level of the day during the measurement period. The solid line represents the sarcopenia group, and the dotted line indicates the no sarcopenia group. Fluctuation: the average of the diurnal range from the minimum glucose level to the maximum glucose level. ${ }^{* *} p<0.01,{ }^{*} p<0.05$.

Next, we examined the glucose profile differences with and without sarcopenia in the cognitive impairment group (Figure A1). Cognitive impairment patients with sarcopenia displayed large glucose fluctuations ( $119.5 \mathrm{mg} / \mathrm{dL}$ vs. $90.7 \mathrm{mg} / \mathrm{dL}, p=0.021)$ and elevated glucose levels $2 \mathrm{~h}$ after breakfast ( $210.6 \mathrm{mg} / \mathrm{dL}$ vs. $177.4 \mathrm{mg} / \mathrm{dL}, p=0.044)$. In the normal cognition group, because only one patient was diagnosed with sarcopenia, we could not examine the association between glucose profiles and sarcopenia. 


\subsection{Differences in Glucose Profiles Based on Sarcopenia Components}

The differences in glucose profiles with and without sarcopenia components in all subjects are shown in Figure 2. Patients with a low muscle mass, low grip strength and slow walking speed displayed larger glucose fluctuations compared to patients without these conditions (low muscle mass: $110.8 \mathrm{mg} / \mathrm{dL}$ vs. $88.1 \mathrm{mg} / \mathrm{dL}, p=0.018$; low grip strength: $104.4 \mathrm{mg} / \mathrm{dL}$ vs. $84.4 \mathrm{mg} / \mathrm{dL}, p=0.005$; and slow walking speed: $136.6 \mathrm{mg} / \mathrm{dL}$ vs. $88.6 \mathrm{mg} / \mathrm{dL}, p=0.003$, respectively). Furthermore, patients with these conditions displayed high glucose levels $2 \mathrm{~h}$ after breakfast (low muscle mass: $203.8 \mathrm{mg} / \mathrm{dL}$ vs. $176.8 \mathrm{mg} / \mathrm{dL}, p=0.020$; low grip strength: $198.1 \mathrm{mg} / \mathrm{dL}$ vs. $171.5 \mathrm{mg} / \mathrm{dL}, p=0.002$; and slow walking speed: $241.8 \mathrm{mg} / \mathrm{dL}$ vs. $177.0 \mathrm{mg} / \mathrm{dL}, p<0.001$, respectively). In addition, patients with low grip strength showed high glucose levels before lunch $(146.2 \mathrm{mg} / \mathrm{dL}$ vs. $116.4 \mathrm{mg} / \mathrm{dL}, p=0.001)$ and before dinner $(145.3 \mathrm{mg} / \mathrm{dL}$ vs. $129.4 \mathrm{mg} / \mathrm{dL}, p=0.034)$, and patients with a slow walking speed showed high glucose levels before dinner (155.2 mg/dL vs. $133.7 \mathrm{mg} / \mathrm{dL}, p=0.041)$.

In the cognitive impairment group, patients with a low muscle mass tended to have large glucose fluctuations and high glucose levels $2 \mathrm{~h}$ after breakfast, but this difference did not reach statistical significance $(111.9 \mathrm{mg} / \mathrm{dL}$ vs. $91.2 \mathrm{mg} / \mathrm{dL}, p=0.076$, and $204.1 \mathrm{mg} / \mathrm{dL}$ vs. $177.1 \mathrm{mg} / \mathrm{dL}, p=0.077$, respectively) (Figure A2). Patients with low grip strength displayed large glucose fluctuations and high glucose levels $2 \mathrm{~h}$ after breakfast and before lunch $(107.4 \mathrm{mg} / \mathrm{dL}$ vs. $85.2 \mathrm{mg} / \mathrm{dL}, p=0.033$, $197.6 \mathrm{mg} / \mathrm{dL}$ vs. $170.0 \mathrm{mg} / \mathrm{dL}, p=0.038$, and $151.4 \mathrm{mg} / \mathrm{dL}$ vs. $121.3 \mathrm{mg} / \mathrm{dL}, p=0.025$, respectively). In addition, patients with a slow walking speed displayed large glucose fluctuations and high glucose levels $2 \mathrm{~h}$ after breakfast $(136.6 \mathrm{mg} / \mathrm{dL}$ vs. $91.4 \mathrm{mg} / \mathrm{dL}, p=0.009$, and $241.8 \mathrm{mg} / \mathrm{dL}$ vs. $176.5 \mathrm{mg} / \mathrm{dL}$, $p=0.001$, respectively).

\subsection{Prevalence of Hypoglycemia and its Association with Sarcopenia}

Hypoglycemia (glucose range: $43-70 \mathrm{mg} / \mathrm{dL}$ ) was observed at 49 measurement points $(1.78 \%$ of all measurement points) in all subjects. Severe hypoglycemic symptoms or events were not observed in this study. Typical hypoglycemic symptoms, such as hand tremor and palpitations, were observed in one normal cognition subject whose glucose level was $45 \mathrm{mg} / \mathrm{dL}$. Hypoglycemia-related symptoms, such as nausea, dizziness, light-headedness, blurred vision and fatigue, were reported at four measurement points in the cognitive impairment group and four measurement points in the normal cognition group.

There was no difference in the frequency of hypoglycemia between patients with and without sarcopenia in all subjects $(1.3 \pm 2.5$ vs. $0.6 \pm 1.1, p=0.884$, Mann-Whitney $U$ test). The effect of mild hypoglycemia (glucose level $\leq 80 \mathrm{mg} / \mathrm{dL}$ or $\leq 90 \mathrm{mg} / \mathrm{dL}$ ) on sarcopenia was also examined. However, there was no difference in the frequency of mild hypoglycemia among the patients (glucose level $\leq 80 \mathrm{mg} / \mathrm{dL} ; 2.4 \pm 3.9$ vs. $1.8 \pm 2.5, p=0.922$, glucose level $\leq 90 \mathrm{mg} / \mathrm{dL} ; 4.9 \pm 6.8$ vs. $4.6 \pm 4.7$, $p=0.741$, Mann-Whitney U test).

We conducted the same analysis in the cognitive impairment group. However, no difference was found in the frequency of hypoglycemia between patients with and without sarcopenia.

\subsection{Association of Glucose Indices with Sarcopenia}

Because the patients with sarcopenia displayed large glucose fluctuations, high glucose levels at $2 \mathrm{~h}$ after breakfast and before lunch, we conducted a regression analysis using the stepwise method to extract the most influential glucose index on sarcopenia. The results revealed glucose fluctuations as the most influential variable on sarcopenia ( $\mathrm{OR}=1.041, p=0.012)$. Therefore, we used glucose fluctuations as an independent variable for the subsequent logistic regression analysis. 


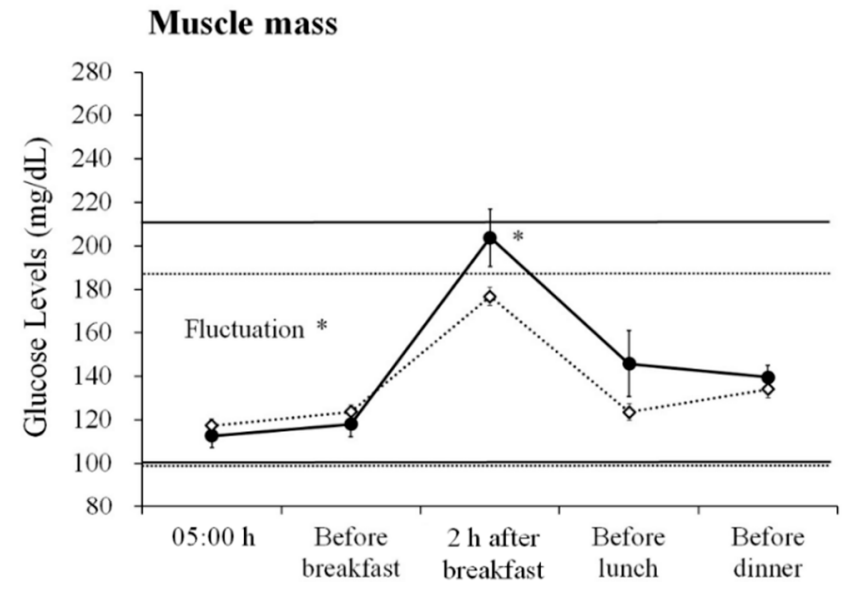

-Low muscle mass $\quad \bowtie$ Normal muscle mass

Grip strength

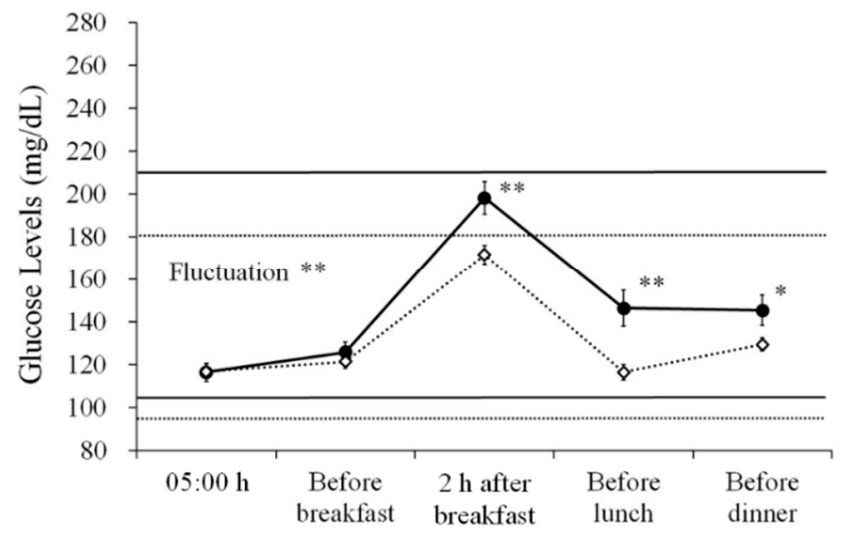

-Low grip strength $\quad \diamond$ Normal grip strength

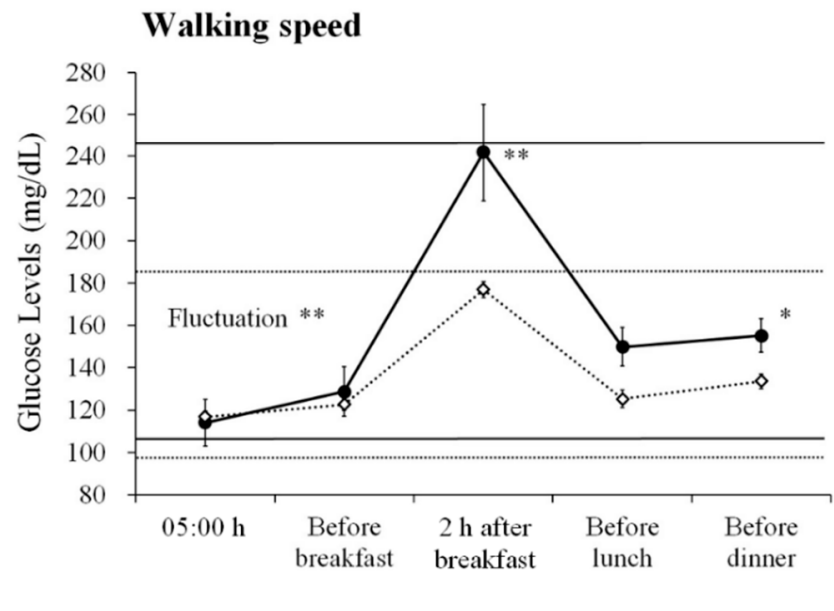

-Slow walking speed $\quad \diamond$ Normal walking speed

Figure 2. Daily glucose profiles based on the sarcopenia components. The figures show the average \pm SE glucose level based on the components of sarcopenia in all participants. ${ }^{* *} p<0.01,{ }^{*} p<0.05$. 
After adjusting for age, $\mathrm{HbA1c}$ level and the presence of diabetic neuropathy, glucose fluctuations were independently associated with sarcopenia (Table 2). Additionally, among the components of sarcopenia, glucose fluctuations were significantly associated with low muscle mass, low grip strength, and slow walking speed.

Table 2. Association of glucose fluctuations with sarcopenia.

\begin{tabular}{|c|c|c|c|c|}
\hline & \multicolumn{4}{|c|}{ Glucose Fluctuations } \\
\hline & Differences * & OR & $95 \%$ CI & $p$-Value \\
\hline No sarcopenia & \multicolumn{4}{|c|}{ Reference } \\
\hline Sarcopenia & $29.3 \mathrm{mg} / \mathrm{dL}$ & 1.045 & $(1.007 ; 1.083)$ & 0.018 \\
\hline Normal muscle mass & \multicolumn{4}{|c|}{ Reference } \\
\hline Low muscle mass & $22.7 \mathrm{mg} / \mathrm{dL}$ & 1.031 & $(1.000 ; 1.064)$ & 0.0499 \\
\hline Normal grip strength & \multicolumn{4}{|c|}{ Reference } \\
\hline Low grip strength & $20.0 \mathrm{mg} / \mathrm{dL}$ & 1.029 & $(1.006 ; 1.053)$ & 0.014 \\
\hline Normal walking speed & \multicolumn{4}{|c|}{ Reference } \\
\hline Slow walking speed & $48.0 \mathrm{mg} / \mathrm{dL}$ & 1.092 & $(1.018 ; 1.172)$ & 0.014 \\
\hline
\end{tabular}

Logistic regression with a step-wise method. The dependent variables were sarcopenia and its components. The independent variable was glucose fluctuations. All analyses were adjusted for age, $\mathrm{HbA} 1 \mathrm{c}$ level and the presence of diabetic neuropathy. * Indicates the differences relative to glucose levels in individuals in the no sarcopenia, normal muscle mass, normal grip strength, and normal walking speed groups. Abbreviations: CI, confidence interval; OR, odds ratio.

In the cognitive impairment group, glucose fluctuations were independently associated with sarcopenia $(\mathrm{OR}=1.038, p=0.035)$. Furthermore, glucose fluctuations were significantly associated with low grip strength ( $\mathrm{OR}=1.034, p=0.049)$ and slow walking speed $(\mathrm{OR}=1.077, p=0.023)$. The association between glucose fluctuation and low muscle mass did not reach statistical significance, which may have been caused by the low statistical power due to the small sample size.

\section{Discussion}

The present study revealed that diabetes patients with cognitive impairment had a high prevalence of sarcopenia. Glucose fluctuations were independently associated with sarcopenia after adjusting for $\mathrm{HbA1c}$ levels and associated factors. Our observation suggests the importance of glucose management by considering glucose fluctuations in older adults with diabetes.

In the current study, the prevalence of sarcopenia was higher in the cognitive impairment group than the normal cognition group. However, diabetes comorbidities and medication were comparable between the groups. Regarding the underlying mechanisms of sarcopenia in diabetes, insulin resistance in peripheral tissues has been suggested $[3,26]$. Insulin resistance is associated with impaired mitochondrial function in muscles, leading to the production of oxidative damage [3]. In addition, increased levels of inflammatory cytokines, such as interleukin (IL)-1, IL-6, and tumor necrosis factor alpha (TNF- $\alpha$ ), are observed in diabetes but are also found in AD patients [27]. These factors are closely related to decreased muscle function [28]. Furthermore, anabolic hormones play a major role in muscle integrity; testosterone decline is found in diabetes patients and also involved in the development of $\mathrm{AD}[3,29]$. More recently, AD-related brain pathology has also been associated with low physical performance [30,31]. Thus, diabetes patients with cognitive impairment have multiple factors that may contribute to the development of sarcopenia.

In this investigation, we found an independent association between glucose fluctuations and sarcopenia in cognitively impaired patients. Acute hyperglycemia increases $A \beta$ production, and altering insulin signaling lead to changes in $A \beta$ levels in the brain [32-34]. Increased levels of $A \beta$ have been also found in the skeletal muscle, which may cause impaired peripheral glucose metabolism $[35,36]$. In addition, glucose fluctuations are a greater trigger of oxidative stress than sustained hyperglycemia, and independently contribute to the development of microvascular complications [37,38]. Because brain tissue of $\mathrm{AD}$ show increased oxidative stress during the course of the disease [39], AD patients are 
more likely to be susceptible to the influence of glucose fluctuations on the brain. In fact, our previous study showed that glucose fluctuations during postprandial periods were independently associated with frontal white matter hyperintensity $(\mathrm{WMH})$ in diabetic patients with $\mathrm{AD}$ but not in patients with normal cognition [40]. Frontal WMH is known to play a predominant role in motor dysfunctions in AD/aMCI patients [41,42]. Furthermore, an association between elevated $2 \mathrm{~h}$ post-load glucose levels evaluated by the oral glucose tolerance test and brain atrophy has also been reported [43]. Thus, brain structural changes associated with glucose fluctuations might further contribute to mobility disabilities in diabetes patients with cognitive impairment.

In this study, the prevalence of sarcopenia was lower than previously reported [3], particularly in the normal cognition group. This can be explained by differences in the measurement method for muscle mass in the current study. Low muscle mass is an essential condition for the AWGS definition of sarcopenia and was measured by calf circumference. A previous study showed that fat-free mass decreases and fat mass increases with aging [44]. However, in older adult with diabetes, muscle mass is even lower than in non-diabetic individuals [45]. Furthermore, higher level of insulin resistance has been associated with low muscle mass and high fat mass [46]. A study using peripheral quantitative computed tomography showed that diabetes patients have a larger intramuscular and intermuscular adipose tissue in calf muscles than individuals without diabetes [47]. Therefore, diabetic patients are considered to have deteriorated muscle quality compared to individuals without diabetes. It seems likely that these muscle changes cannot be correctly measured with calf circumference. Although, calf circumference is considered suitable for evaluating muscle mass, our observations suggest that calf circumference may be difficult to accurately estimate the muscle mass of patients with diabetes.

We found no association between hypoglycemia and sarcopenia. Diabetes patients who experienced hypoglycemic events had a high prevalence of comorbidities, disabilities, and malnutrition, and were often treated with insulin therapy and use of polypharmacy [10]. However, in this study, no difference was identified in these parameters between patients with and without hypoglycemia. The study participants had relatively well-controlled glucose levels, and severe hypoglycemic events were not observed. Therefore, we could not detect a sufficient impact of hypoglycemia. In fact, hospitalization due to severe hypoglycemia can cause further deterioration in physical function [10]. Hypoglycemic symptoms in older patients are mild or asymptomatic, and episodes are less likely to manifest [10]. We further addressed concerns about repeated mild hypoglycemia but found no association of mild hypoglycemia with sarcopenia.

Currently, sarcopenia and frailty are considered a third category of diabetes-related complications in addition to the traditional microvascular and macrovascular disease [4]. Because muscle weakness and impaired physical function resulting from sarcopenia are major physiological components of frailty, these conditions often overlap $[3,48]$. Some studies reported that frailty and cognitive decline are reciprocally related and suggested that they share underlying pathophysiological mechanisms, including AD pathology, chronic inflammation, mood disorder, and co-morbidities [49-51]. Thus, patients with cognitive impairment are at high risk of vulnerability due to diverse extrinsic and intrinsic conditions. Recently, some types of interventions, such as physical exercise, nutritional therapy, and multicomponent interventions, to prevent frailty have been attempted [52]. Exercise training has benefits for physical capacity and cognitive performance [53], improves skeletal muscle insulin sensitivity and increases muscle mass in frail older adults [54]. Furthermore, the benefits of resistance training in improving glycemic status and muscle strength have been reported [55]. Therefore, in addition to glucose management using medications appropriately to avoid glucose fluctuations, multimodal interventions would be beneficial to delay or prevent disability in older diabetic patients.

This study has several limitations. First, because this study had a cross-sectional design, causal relationships should be carefully considered. Second, the sample size was relatively small. Nevertheless, our results revealed the independent association between glucose fluctuations and sarcopenia, even after adjusting for several confounding factors. Furthermore, our sample size was largely comparable to that of a previous study that identified an association between altered glucose dynamics and frailty [56]. Additional 
studies with a large cohort estimated by calculation of the appropriate sample size are needed to confirm our findings. Third, the cognitive impairment group was assigned based on the criteria of probable or possible $\mathrm{AD}$ and $\mathrm{aMCI}[15,16]$, but biomarkers for $\mathrm{AD}$ pathology were not assessed in this study. $\mathrm{A}$ biological definition based on neuroimaging with positron emission tomography and cerebrospinal fluid biomarkers is necessary to achieve a precise diagnosis [57,58]. Fourth, SMBG was used evaluate glucose levels, but continuous glucose monitoring (CGM) might more accurately represent the glucose profiles [59]. However, CGM in patients with cognitive impairment is difficult. Because we measured glucose levels on 8 separate days during the two-month period, our data could reflect the characteristics of glucose profiles over this period. Finally, we did not use elaborate equipment to evaluate muscle mass and walking speed. It is suitable to measure muscle mass using bioimpedance analysis [22]. Regarding walking speed, our evaluation was based on self-reported answers related to road crossing. To safely cross the road while the traffic signal is green, a pedestrian walking speed of $1.2 \mathrm{~m} / \mathrm{s}$ is required [60]. This value is the same as the cut-off for slow walking speed in Japanese elderly individuals [22].

\section{Conclusions}

The prevalence of sarcopenia was high in diabetes patients with cognitive impairment. Glucose fluctuations were independently associated with sarcopenia, particular with low muscle mass, low grip strength and slow walking speed. Our study described the characteristic glucose profiles in older diabetes patients with sarcopenia. To maintain functional ability in older diabetes patients, confirmation of our data in future longitudinal studies with a larger cohort is required.

Author Contributions: Conceptualization, N.O. and T.S.; formal analysis, N.O.; investigation and data curation, T.S., S.K., T.T., H.T., S.S., H.M., A.S., and M.K. (Manabu Kokubo); resources, S.N.; writing-original draft preparation, N.O.; writing-review and editing T.S.; supervision, K.T., H.U., and M.K. (Masafumi Kuzuya); funding acquisition, N.O. and T.S.

Funding: This work was supported by a grant from the Research Funding for Longevity Sciences (27-21, 30-1, 30-42) from the National Center for Geriatrics and Gerontology (NCGG), and the Japan Agency for Medical Research and Development (18dk0207027h0003).

Acknowledgments: The authors thank the NCGG Biobank for performing quality control of the clinical data and blood samples. We are also grateful to Kaori Inaguma (Center for Comprehensive Care and Research on Memory Disorders, NCGG) for their assistance with the collection of the clinical data.

Conflicts of Interest: The authors declare no conflict of interest.

\section{Appendix A}

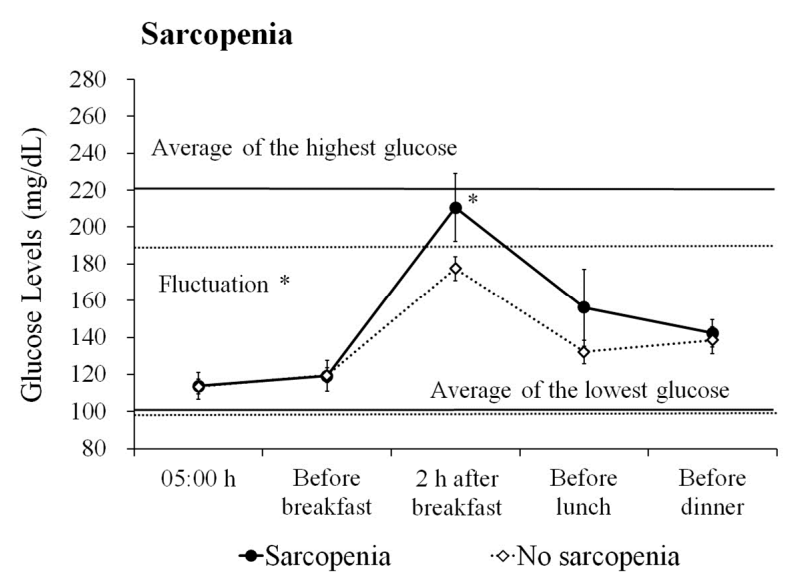

Figure A1. Daily glucose profiles based on sarcopenia in the cognitive impairment group. The figure shows the average \pm standard error (SE) glucose level. Average of the highest glucose level: the average of the maximum glucose level of the day during the measurement period. Average of the lowest glucose level: the average of the minimum glucose level of the day during the measurement period. The solid line represents the sarcopenia group, and the dotted line indicates the no sarcopenia group. Fluctuation: the average of the diurnal range from the minimum glucose level to the maximum glucose level. ${ }^{*} p<0.05$. 


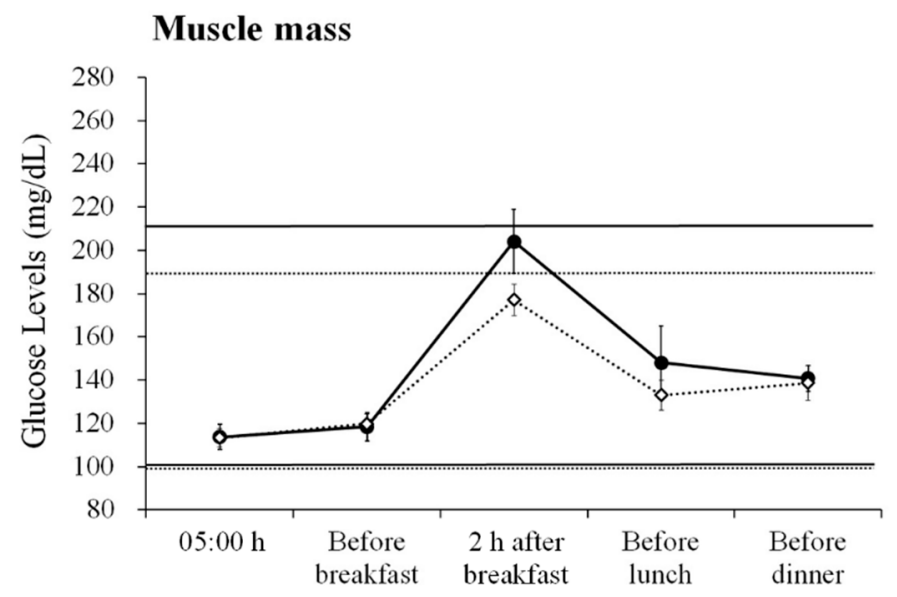

$\bullet$ Low muscle mass $\quad \diamond \cdot$ Normal muscle mass

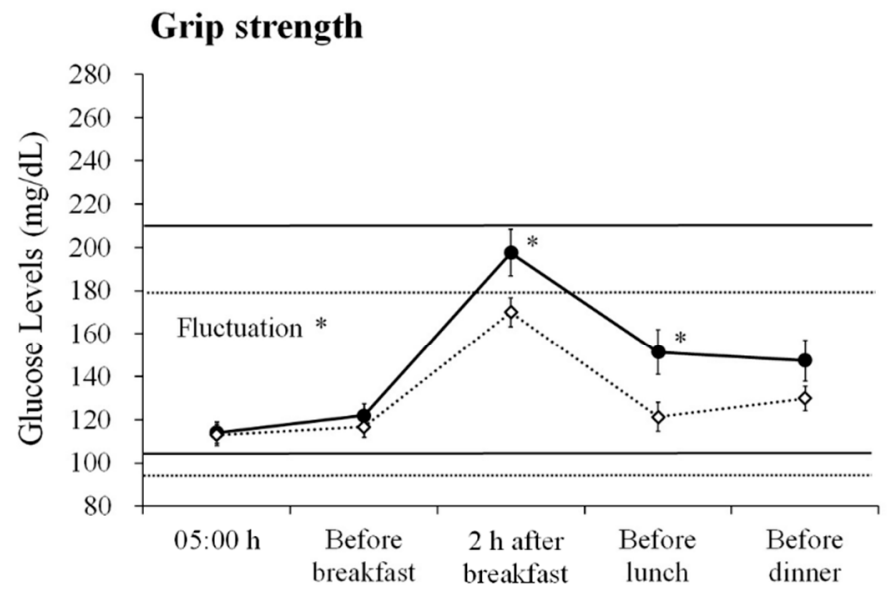

$\bullet$ Low grip strength $\quad \diamond$ Normal grip strength

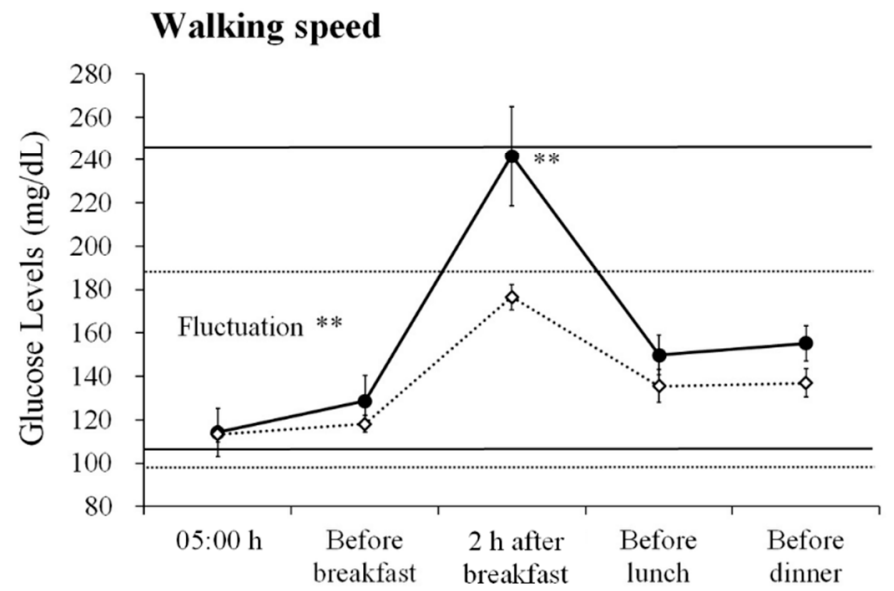

-Slow walking speed $\bullet$ Normal walking speed

Figure A2. Daily glucose profiles based on the sarcopenia components in the cognitive impairment group. The figures show the average \pm SE glucose level based on the components of sarcopenia. ** $p<0.01, * p<0.05$. 


\section{References}

1. Cruz-Jentoft, A.J.; Bahat, G.; Bauer, J.; Boirie, Y.; Bruyere, O.; Cederholm, T.; Cooper, C.; Landi, F.; Rolland, Y.; Sayer, A.A.; et al. Sarcopenia: revised European consensus on definition and diagnosis. Age Ageing 2018, 48, 16-31. [CrossRef] [PubMed]

2. Han, A.; Bokshan, S.L.; Marcaccio, S.E.; DePasse, J.M.; Daniels, A.H. Diagnostic Criteria and Clinical Outcomes in Sarcopenia Research: A Literature Review. J. Clin. Med. 2018, 7, E70. [CrossRef] [PubMed]

3. Morley, J.E.; Malmstrom, T.K.; Rodriguez-Manas, L.; Sinclair, A.J. Frailty, sarcopenia and diabetes. J. Am. Med. Dir. Assoc. 2014, 15, 853-859. [CrossRef] [PubMed]

4. Sinclair, A.J.; Abdelhafiz, A.H.; Rodriguez-Manas, L. Frailty and sarcopenia-newly emerging and high impact complications of diabetes. J. Diabetes Complicat. 2017, 31, 1465-1473. [CrossRef] [PubMed]

5. Yoon, J.W.; Ha, Y.C.; Kim, K.M.; Moon, J.H.; Choi, S.H.; Lim, S.; Park, Y.J.; Lim, J.Y.; Kim, K.W.; Park, K.S.; et al. Hyperglycemia Is Associated with Impaired Muscle Quality in Older Men with Diabetes: The Korean Longitudinal Study on Health and Aging. Diabetes Metab. J. 2016, 40, 140-146. [CrossRef] [PubMed]

6. Leenders, M.; Verdijk, L.B.; van der Hoeven, L.; Adam, J.J.; van Kranenburg, J.; Nilwik, R.; van Loon, L.J. Patients with type 2 diabetes show a greater decline in muscle mass, muscle strength, and functional capacity with aging. J. Am. Med. Dir. Assoc. 2013, 14, 585-592. [CrossRef] [PubMed]

7. Kalyani, R.R.; Metter, E.J.; Egan, J.; Golden, S.H.; Ferrucci, L. Hyperglycemia predicts persistently lower muscle strength with aging. Diabetes Care 2015, 38, 82-90. [CrossRef] [PubMed]

8. Munshi, M.N.; Segal, A.R.; Slyne, C.; Samur, A.A.; Brooks, K.M.; Horton, E.S. Shortfalls of the use of HbA1C-derived eAG in older adults with diabetes. Diabetes Res. Clin. Pract. 2015, 110, 60-65. [CrossRef] [PubMed]

9. Munshi, M.N.; Slyne, C.; Segal, A.R.; Saul, N.; Lyons, C.; Weinger, K. Liberating A1C goals in older adults may not protect against the risk of hypoglycemia. J. Diabetes Complicat. 2017, 31, 1197-1199. [CrossRef] [PubMed]

10. Abdelhafiz, A.H.; McNicholas, E.; Sinclair, A.J. Hypoglycemia, frailty and dementia in older people with diabetes: Reciprocal relations and clinical implications. J. Diabetes Complicat. 2016, 30, 1548-1554. [CrossRef] [PubMed]

11. Burns, J.M.; Johnson, D.K.; Watts, A.; Swerdlow, R.H.; Brooks, W.M. Reduced lean mass in early Alzheimer disease and its association with brain atrophy. Arch. Neurol. 2010, 67, 428-433. [CrossRef] [PubMed]

12. Fujisawa, C.; Umegaki, H.; Okamoto, K.; Nakashima, H.; Kuzuya, M.; Toba, K.; Sakurai, T. Physical Function Differences Between the Stages From Normal Cognition to Moderate Alzheimer Disease. J. Am. Med. Dir. Assoc. 2017, 18, e9-e368. [CrossRef] [PubMed]

13. Sugimoto, T.; Nakamura, A.; Kato, T.; Iwata, K.; Saji, N.; Arahata, Y.; Hattori, H.; Bundo, M.; Ito, K.; Niida, S.; et al. Decreased Glucose Metabolism in Medial Prefrontal Areas is Associated with Nutritional Status in Patients with Prodromal and Early Alzheimer's Disease. J. Alzheimers Dis. 2017, 60, 225-233. [CrossRef] [PubMed]

14. Sugimoto, T.; Ono, R.; Murata, S.; Saji, N.; Matsui, Y.; Niida, S.; Toba, K.; Sakurai, T. Prevalence and associated factors of sarcopenia in elderly subjects with amnestic mild cognitive impairment or Alzheimer disease. Curr. Alzheimer Res. 2016, 13, 718-726. [CrossRef] [PubMed]

15. McKhann, G.M.; Knopman, D.S.; Chertkow, H.; Hyman, B.T.; Jack, C.R., Jr.; Kawas, C.H.; Klunk, W.E.; Koroshetz, W.J.; Manly, J.J.; Mayeux, R.; et al. The diagnosis of dementia due to Alzheimer's disease: recommendations from the National Institute on Aging-Alzheimer's Association workgroups on diagnostic guidelines for Alzheimer's disease. Alzheimers Dement. 2011, 7, 263-269. [CrossRef] [PubMed]

16. Petersen, R.C.; Doody, R.; Kurz, A.; Mohs, R.C.; Morris, J.C.; Rabins, P.V.; Ritchie, K.; Rossor, M.; Thal, L.; Winblad, B. Current concepts in mild cognitive impairment. Arch. Neurol. 2001, 58, 1985-1992. [CrossRef] [PubMed]

17. Gnjidic, D.; Hilmer, S.N.; Blyth, F.M.; Naganathan, V.; Waite, L.; Seibel, M.J.; McLachlan, A.J.; Cumming, R.G.; Handelsman, D.J.; Le Couteur, D.G. Polypharmacy cutoff and outcomes: five or more medicines were used to identify community-dwelling older men at risk of different adverse outcomes. J. Clin. Epidemiol. 2012, 65, 989-995. [CrossRef] [PubMed]

18. Folstein, M.F.; Folstein, S.E.; McHugh, P.R. "Mini-mental state". A practical method for grading the cognitive state of patients for the clinician. J. Psychiatr. Res. 1975, 12, 189-198. [CrossRef] 
19. Sakurai, T.; Iimuro, S.; Sakamaki, K.; Umegaki, H.; Araki, A.; Ohashi, Y.; Ito, H.; Japanese Elderly Diabetes Intervention Trial Study Group. Risk factors for a 6-year decline in physical disability and functional limitations among elderly people with type 2 diabetes in the Japanese Elderly Diabetes Intervention Trial. Geriatr. Gerontol. Int. 2012, 12, 117-126. [CrossRef] [PubMed]

20. Monnier, L.; Colette, C.; Dunseath, G.J.; Owens, D.R. The loss of postprandial glycemic control precedes stepwise deterioration of fasting with worsening diabetes. Diabetes Care 2007, 30, 263-269. [CrossRef] [PubMed]

21. Workgroup on Hypoglycemia, American Diabetes Association. Defining and reporting hypoglycemia in diabetes: a report from the American Diabetes Association Workgroup on Hypoglycemia. Diabetes Care 2005, 28, 1245-1249. [CrossRef]

22. Chen, L.K.; Liu, L.K.; Woo, J.; Assantachai, P.; Auyeung, T.W.; Bahyah, K.S.; Chou, M.Y.; Chen, L.Y.; Hsu, P.S.; Krairit, O.; et al. Sarcopenia in Asia: consensus report of the Asian Working Group for Sarcopenia. J. Am. Med. Dir. Assoc. 2014, 15, 95-101. [CrossRef] [PubMed]

23. Pagotto, V.; Silveira, E.A. Methods, diagnostic criteria, cutoff points, and prevalence of sarcopenia among older people. ScientificWorldJournal 2014, 2014, 231312. [CrossRef] [PubMed]

24. Kawakami, R.; Murakami, H.; Sanada, K.; Tanaka, N.; Sawada, S.S.; Tabata, I.; Higuchi, M.; Miyachi, M. Calf circumference as a surrogate marker of muscle mass for diagnosing sarcopenia in Japanese men and women. Geriatr. Gerontol. Int. 2015, 15, 969-976. [CrossRef] [PubMed]

25. Okochi, J.; Toba, K.; Takahashi, T.; Matsubayashi, K.; Nishinaga, M.; Takahashi, R.; Ohrui, T. Simple screening test for risk of falls in the elderly. Geriatr. Gerontol. Int. 2006, 6, 223-227. [CrossRef]

26. Abbatecola, A.M.; Paolisso, G.; Fattoretti, P.; Evans, W.J.; Fiore, V.; Dicioccio, L.; Lattanzio, F. Discovering pathways of sarcopenia in older adults: a role for insulin resistance on mitochondria dysfunction. J. Nutr. Health Aging 2011, 15, 890-895. [CrossRef] [PubMed]

27. Ferreira, S.T.; Clarke, J.R.; Bomfim, T.R.; De Felice, F.G. Inflammation, defective insulin signaling, and neuronal dysfunction in Alzheimer's disease. Alzheimers Dement 2014, 10, S76-S83. [CrossRef] [PubMed]

28. Ogawa, S.; Yakabe, M.; Akishita, M. Age-related sarcopenia and its pathophysiological bases. Inflamm. Regen. 2016, 36, 17. [CrossRef] [PubMed]

29. Asih, P.R.; Tegg, M.L.; Sohrabi, H.; Carruthers, M.; Gandy, S.E.; Saad, F.; Verdile, G.; Ittner, L.M.; Martins, R.N. Multiple Mechanisms Linking Type 2 Diabetes and Alzheimer's Disease: Testosterone as a Modifier. J. Alzheimers Dis. 2017, 59, 445-466. [CrossRef] [PubMed]

30. Buchman, A.S.; Yu, L.; Wilson, R.S.; Boyle, P.A.; Schneider, J.A.; Bennett, D.A. Brain pathology contributes to simultaneous change in physical frailty and cognition in old age. J. Gerontol. A Biol. Sci. Med. Sci. 2014, 69, 1536-1544. [CrossRef] [PubMed]

31. Del Campo, N.; Payoux, P.; Djilali, A.; Delrieu, J.; Hoogendijk, E.O.; Rolland, Y.; Cesari, M.; Weiner, M.W.; Andrieu, S.; Vellas, B.; et al. Relationship of regional brain $\beta$-amyloid to gait speed. Neurology 2016, 86, 36-43. [CrossRef] [PubMed]

32. Sato, N.; Morishita, R. The roles of lipid and glucose metabolism in modulation of $\beta$-amyloid, tau, and neurodegeneration in the pathogenesis of Alzheimer disease. Front. Aging Neurosci. 2015, 7, 199. [CrossRef] [PubMed]

33. Vekrellis, K.; Ye, Z.; Qiu, W.Q.; Walsh, D.; Hartley, D.; Chesneau, V.; Rosner, M.R.; Selkoe, D.J. Neurons regulate extracellular levels of amyloid beta-protein via proteolysis by insulin-degrading enzyme. J. Neurosci. 2000, 20, 1657-1665. [CrossRef] [PubMed]

34. Macauley, S.L.; Stanley, M.; Caesar, E.E.; Yamada, S.A.; Raichle, M.E.; Perez, R.; Mahan, T.E.; Sutphen, C.L.; Holtzman, D.M. Hyperglycemia modulates extracellular amyloid- $\beta$ concentrations and neuronal activity in vivo. J. Clin. Investig. 2015, 125, 2463-2467. [CrossRef] [PubMed]

35. Roher, A.E.; Esh, C.L.; Kokjohn, T.A.; Castano, E.M.; Van Vickle, G.D.; Kalback, W.M.; Patton, R.L.; Luehrs, D.C.; Daugs, I.D.; Kuo, Y.M.; et al. Amyloid beta peptides in human plasma and tissues and their significance for Alzheimer's disease. Alzheimers Dement 2009, 5, 18-29. [CrossRef] [PubMed]

36. Shinohara, M.; Sato, N. Bidirectional interactions between diabetes and Alzheimer's disease. Neurochem. Int. 2017, 108, 296-302. [CrossRef] [PubMed]

37. Monnier, L.; Mas, E.; Ginet, C.; Michel, F.; Villon, L.; Cristol, J.P.; Colette, C. Activation of oxidative stress by acute glucose fluctuations compared with sustained chronic hyperglycemia in patients with type 2 diabetes. JAMA 2006, 295, 1681-1687. [CrossRef] [PubMed] 
38. Smith-Palmer, J.; Brandle, M.; Trevisan, R.; Orsini Federici, M.; Liabat, S.; Valentine, W. Assessment of the association between glycemic variability and diabetes-related complications in type 1 and type 2 diabetes. Diabetes Res. Clin. Pract. 2014, 105, 273-284. [CrossRef] [PubMed]

39. Gella, A.; Durany, N. Oxidative stress in Alzheimer disease. Cell Adh. Migr. 2009, 3, 88-93. [CrossRef] [PubMed]

40. Ogama, N.; Sakurai, T.; Kawashima, S.; Tanikawa, T.; Tokuda, H.; Satake, S.; Miura, H.; Shimizu, A.; Kokubo, M.; Niida, S.; et al. Postprandial Hyperglycemia is Associated with White Matter Hyperintensity and Brain Atrophy in Older Patients with Type 2 Diabetes Mellitus. Front. Aging Neurosci.. 2018, 10, 273. [CrossRef] [PubMed]

41. Ogama, N.; Sakurai, T.; Shimizu, A.; Toba, K. Regional white matter lesions predict falls in patients with amnestic mild cognitive impairment and Alzheimer's disease. J. Am. Med. Dir. Assoc. 2014, 15, 36-41. [CrossRef] [PubMed]

42. Ogama, N.; Sakurai, T.; Nakai, T.; Niida, S.; Saji, N.; Toba, K.; Umegaki, H.; Kuzuya, M. Impact of frontal white matter hyperintensity on instrumental activities of daily living in elderly women with Alzheimer disease and amnestic mild cognitive impairment. PLoS ONE 2017, 12, e0172484. [CrossRef] [PubMed]

43. Hirabayashi, N.; Hata, J.; Ohara, T.; Mukai, N.; Nagata, M.; Shibata, M.; Gotoh, S.; Furuta, Y.; Yamashita, F.; Yoshihara, K.; et al. Association Between Diabetes and Hippocampal Atrophy in Elderly Japanese: The Hisayama Study. Diabetes Care 2016, 39, 1543-1549. [CrossRef] [PubMed]

44. Jackson, A.S.; Janssen, I.; Sui, X.; Church, T.S.; Blair, S.N. Longitudinal changes in body composition associated with healthy ageing: men, aged 20-96 years. Br. J. Nutr. 2012, 107, 1085-1091. [CrossRef] [PubMed]

45. Kim, K.S.; Park, K.S.; Kim, M.J.; Kim, S.K.; Cho, Y.W.; Park, S.W. Type 2 diabetes is associated with low muscle mass in older adults. Geriatr. Gerontol. Int. 2014, 14, 115-121. [CrossRef] [PubMed]

46. Kim, K.; Park, S.M. Association of muscle mass and fat mass with insulin resistance and the prevalence of metabolic syndrome in Korean adults: a cross-sectional study. Sci. Rep. 2018, 8, 2703. [CrossRef] [PubMed]

47. Scott, D.; de Courten, B.; Ebeling, P.R. Sarcopenia: a potential cause and consequence of type 2 diabetes in Australia's ageing population? Med. J. Aust. 2016, 205, 329-333. [CrossRef] [PubMed]

48. Fried, L.P.; Tangen, C.M.; Walston, J.; Newman, A.B.; Hirsch, C.; Gottdiener, J.; Seeman, T.; Tracy, R.; Kop, W.J.; Burke, G.; et al. Frailty in older adults: evidence for a phenotype. J. Gerontol. A Biol. Sci. Med. Sci. 2001, 56, M146-M156. [CrossRef] [PubMed]

49. Koch, G.; Belli, L.; Giudice, T.L.; Lorenzo, F.D.; Sancesario, G.M.; Sorge, R.; Bernardini, S.; Martorana, A. Frailty among Alzheimer's disease patients. CNS Neurol. Disord. Drug Targets 2013, 12, 507-511. [CrossRef] [PubMed]

50. Robertson, D.A.; Savva, G.M.; Kenny, R.A. Frailty and cognitive impairment-a review of the evidence and causal mechanisms. Ageing Res. Rev. 2013, 12, 840-851. [CrossRef] [PubMed]

51. Wallace, L.; Theou, O.; Rockwood, K.; Andrew, M.K. Relationship between frailty and Alzheimer's disease biomarkers: A scoping review. Alzheimers Dement. 2018, 10, 394-401. [CrossRef] [PubMed]

52. Walston, J.; Buta, B.; Xue, Q.L. Frailty Screening and Interventions: Considerations for Clinical Practice. Clin. Geriatr. Med. 2018, 34, 25-38. [CrossRef] [PubMed]

53. Langlois, F.; Vu, T.T.; Chassé, K.; Dupuis, G.; Kergoat, M.J.; Bherer, L. Benefits of physical exercise training on cognition and quality of life in frail older adults. J. Gerontol. B. Psychol. Sci. Soc. Sci. 2013, 68, 400-404. [CrossRef] [PubMed]

54. Bucci, M.; Huovinen, V.; Guzzardi, M.A.; Koskinen, S.; Raiko, J.R.; Lipponen, H.; Ahsan, S.; Badeau, R.M.; Honka, M.J.; Koffert, J.; et al. Resistance training improves skeletal muscle insulin sensitivity in elderly offspring of overweight and obese mothers. Diabetologia 2016, 59, 77-86. [CrossRef] [PubMed]

55. Lee, J.; Kim, D.; Kim, C. Resistance Training for Glycemic Control, Muscular Strength, and Lean Body Mass in Old Type 2 Diabetic Patients: A Meta-Analysis. Diabetes Ther. 2017, 8, 459-473. [CrossRef] [PubMed]

56. Kalyani, R.R.; Varadhan, R.; Weiss, C.O.; Fried, L.P.; Cappola, A.R. Frailty status and altered glucose-insulin dynamics. J. Gerontol. A Biol. Sci. Med. Sci. 2012, 67, 1300-1306. [CrossRef] [PubMed]

57. Dubois, B.; Feldman, H.H.; Jacova, C.; Hampel, H.; Molinuevo, J.L.; Blennow, K.; DeKosky, S.T.; Gauthier, S.; Selkoe, D.; Bateman, R.; et al. Advancing research diagnostic criteria for Alzheimer's disease: the IWG-2 criteria. Lancet Neurol. 2014, 13, 614-629. [CrossRef] 
58. Jack, C.R., Jr.; Bennett, D.A.; Blennow, K.; Carrillo, M.C.; Dunn, B.; Haeberlein, S.B.; Holtzman, D.M.; Jagust, W.; Jessen, F.; Karlawish, J.; et al. NIA-AA Research Framework: Toward a biological definition of Alzheimer's disease. Alzheimers Dement. 2018, 14, 535-562. [CrossRef] [PubMed]

59. Bergenstal, R.M. Glycemic Variability and Diabetes Complications: Does It Matter? Simply Put, There Are Better Glycemic Markers! Diabetes Care 2015, 38, 1615-1621. [CrossRef] [PubMed]

60. Donoghue, O.A.; Dooley, C.; Kenny, R.A. Usual and Dual-Task Walking Speed: Implications for Pedestrians Crossing the Road. J. Aging Health 2016, 28, 850-862. [CrossRef] [PubMed]

2019 by the authors. Licensee MDPI, Basel, Switzerland. This article is an open access article distributed under the terms and conditions of the Creative Commons Attribution (CC BY) license (http:// creativecommons.org/licenses/by/4.0/). 